\title{
Rheological properties investigation of bitumen modified with nanosilica and polyethylene polymer
}

\author{
Nura Bala*, Madzlan Napiah, Ibrahim Kamaruddin, Nasiru Danlami \\ Department of Civil and Environmental Engineering, Universiti Teknologi PETRONAS, 32610 Bandar Seri Iskandar, Perak, \\ Malaysia
}

\section{A R T I C L E IN F O}

\section{Article history:}

Received 29 June 2017

Received in revised form

11 September 2017

Accepted 12 September 2017

\section{Keywords:}

Nanosilica

Polyethylene

Storage stability

Rheology

Aging

\begin{abstract}
A B S T R A C T
Performance of bituminous binders in terms of rutting and fatique is known to be related with rheological characteristics of asphalt binders. To enhance the rheological properties of binder, a modification using composite polymer and inorganic nanosilica becomes recognized as it highly improves the flow and deformation of the modified binders. This study investigates the application of polyethylene polymer and inorganic nanosilica for enhancing rheological properties as well as the oxidative aging resistance of asphalt binders. Conventional and Superpave binder test techniques. Using dynamic shear rheometer (DSR) was used to investigate the performance and rheological behaviors of the nanocomposite-modified binders. Changes in chemical bonding and morphological properties due to nanosilica were also investigated using Fourier transform infrared spectroscopy (FT-IR) and field emission scanning electron microscopy (FE-SEM). Nanosilica was added into polymer modified bitumen at different percentages (1\% to $6 \%$ ) by weight of bitumen binder. Results of the investigations show that composite nanosilica/polyethylene modified binders will not undergo phase separation during storage due to improved viscoelastic properties. The Superpave rutting parameter shows that nanosilica modified binders have higher resistance to permanent deformation both before and after rolling thin film oven (RTFOT) aging. FE-SEM and FT-IR investigation shows that nanosilica modified binders are less susceptible to oxidative aging hardening.
\end{abstract}

(C) 2017 The Authors. Published by IASE. This is an open access article under the CC BY-NC-ND license (http://creativecommons.org/licenses/by-nc-nd/4.0/).

\section{Introduction}

Bitumen is made of an extremely complex mixture of hydrocarbons and its behavior entirely depends on temperature and loading time (Bala and Kamaruddin, 2016; Yao et al., 2012). Bitumen as a colloidal system, it consists of maltenes which are oily medium with lower molecular weight and asphaltene micelles with high molecular weights which are dispersed in the maltenes (Petersen, 2000). Increase in number of traffic and axle loads globally together with poor performance of unmodified bitumen under different weather conditions results in placing much emphasis in bitumen modification to minimize the effects of moisture damages, deformations and fatigue cracking (Sengoz and Isikyakar, 2008). Polymers such as thermoplastic elastomers and plastomers

\footnotetext{
* Corresponding Author.

Email Address: nura.bala_g03311@utp.edu.my (N. Bala) https://doi.org/10.21833/ijaas.2017.010.023

2313-626X/C 2017 The Authors. Published by IASE.

This is an open access article under the CC BY-NC-ND license

(http://creativecommons.org/licenses/by-nc-nd/4.0/)
}

were found to be among the best materials for bitumen modification after yielding several improvements on the modified binders (Airey, 2003). The major benefits recorded in applying polymers are a reduction in temperature sensitivity, increasing resistance to permanent deformation, higher stiffness during high temperature, good resistant to moisture, resistance to cracking at lower temperatures and longer fatigue life (Zhu et al., 2014).

Common polymers used in modification of bitumen binders are polyolefins group of polymers such as polyethylenes, these includes; high density, low-density as well as linear low density polyethylene polymers and polypropylenes with their copolymers (Fang et al., 2008; Punith and Veeraragavan, 2010). Polyolefins polymers when added to bitumen provide several benefits such as enhancement in properties during the service life of the pavement, improvement in thermo-mechanical resistance, increase in adhesion and elasticity of binder (Fawcett et al., 1999; Pérez-Lepe et al., 2005).

Despite the improvements achieved with polymers, several challenges still exist. The major 
problems related to polymer modified bitumen are a lack of morphological stability during hot storage (phase separation), poor resistance to aging (oxidation), poor compatibility with bitumen and the high cost of modification among others (Ouyang et al., 2006; Zhu et al., 2014).

Recently high number of researches were conducted to investigate if the application of optimum physical characteristics of nanomaterials can make them suitable for bitumen modification, and the results indicate that nanomaterials can enhance bituminous binder properties due to their excellent properties like small particle size which makes them easily blend and more compatible with bitumen (Mahdi et al., 2013; Yang and Tighe, 2013).

Currently, composite nanosilica/polymer modification draws attention as the best alternative to polymers for bitumen modification (Yusoff et al., 2014). Composite nanomaterial/polymer modification is generally more cost effective as it reduces the quantities of polymer and nanomaterial used, at the same time increasing compatibility of polymers with bitumen (Yu et al., 2015). The most common nanomaterials used for bitumen modification includes carbon nanotubes (CNT), nano titanium dioxide $\left(\mathrm{TiO}_{2}\right)$, nanoclay (OMMT), nano calcium trioxocarbonate $\left(\mathrm{CaCO}_{3}\right)$, nano silicon oxide $\left(\mathrm{SiO}_{2}\right)$ and nano zinc oxide (ZnO) (Fang et al., 2013). However, due to the possibility of forming time dependent segregation as a result of poor mixing among the composite materials, the composite modification with nanomaterials requires the use of high shear energy for mixing rather than ordinary mixing techniques (Santagata et al., 2012).

The inorganic nanosilica material is generally utilized due to its high beneficial properties which include large surface area, excellent dispersion ability, high absorption, excellent stability and high chemical purity (Bala et al., 2017; Yao et al., 2012). Nanosilica composites recently attracted scientific research interest due to its greatest benefit of reduction in the cost of production and excellent performance features (Yusoff et al., 2014). Nowadays, due to high surface area and stability of nanosilica, it is widely used as inorganic filler in polymers and bitumen binder to enhance properties of polymers and bituminous binder materials (Fini et al., 2015; Yang and Tighe, 2013).

Nanosilica becomes very attractive for application in bitumen modification, because the surface of nanosilica is more chemically active with high polarity unlike other nanomaterials (Yao et al., 2012; Fini et al., 2015). Nano silica has strong surface free energy and its interface atoms are arranged in a disordered manner which allows for these atoms to be bonded strongly to other outside atoms by external forces (Fang et al., 2013).

Several research have been conducted on rheological properties of polymer modified binders, however, there are limited experimental studies on evaluation of rheological and oxidative aging effects of nanomaterials on polymer modified binders. The main objectives of this study are to characterize the properties of composite nanosilica/polyethylene modified binder through conventional and empirical techniques as well as evaluation of the storage stability and aging properties by assessing the aging indices of the modified binders.

\section{Materials and modification process}

\subsection{Materials}

The base bitumen used in this study is $80 / 100$ penetration grade. The physical properties of the base bitumen binder are presented in Table 1. A polymer linear low density polyethylene (LLDPE) in pellet form was used for the preparation of composite modified blends.

Table 1: Physical properties of base binder

\begin{tabular}{cc}
\hline Physical Property & Value \\
\hline Penetration $\left(25^{\circ} \mathrm{C}, 100 \mathrm{~g}, 5 \mathrm{~s}, 0.1 \mathrm{~mm}\right)$ & $84 \mathrm{dmm}$ \\
Softening point temperature & $42^{\circ} \mathrm{C}$ \\
Ductility at $25^{\circ} \mathrm{C}$ & $>150 \mathrm{~cm}$ \\
Viscosity at $135^{\circ} \mathrm{C}$ & 0.64 Pa.s \\
Specific gravity & 1.03 \\
\hline
\end{tabular}

The properties of inorganic nanosilica used in this study are presented in Table 2 .

Table 2: Physical properties of nanosilica

\begin{tabular}{cc}
\hline Physical Property & Value \\
\hline Appearance & High dispersive white powder \\
Hydrophobicity & Strong hydrophobicity \\
$\mathrm{SiO}_{2}$ content $(\%)\left(950^{\circ} \mathrm{C}, 2 \mathrm{~h}\right)$ & 99.8 \\
Purity $(\%)$ & $>99.9$ \\
Loss of ignition $(\%)$ & $\leq 6$ \\
Surface density $(\mathrm{g} / \mathrm{ml})$ & 0.15 \\
Average Particle size $(\mathrm{nm})$ & $10-25$ \\
PH value & $6.5-7.5$ \\
Specific surface area $\left(\mathrm{m}^{2} / \mathrm{g}\right)$ & $100 \pm 25$ \\
\hline
\end{tabular}

\subsection{Preparation of composite modified binder}

The composite nanosilica/polymer modified binders was prepared by modifying the optimum concentration of $6 \%$ LLDPE with the addition of $1 \%$, to $6 \%$ nanosilica by weight of bitumen binder respectively. Bitumen binder was first heated in an oven at a temperature rate of $150^{\circ} \mathrm{C}$ until it was completely melted. For the composites mixing a propeller blade bench top multimix high shear mixer was used at a high shear rate of $4000 \mathrm{rpm}$ for 2 hours. During the mixing process, the temperature was maintained at a rate of $150 \pm 5^{\circ} \mathrm{C}$ throughout.

\section{Experimentation methods}

\subsection{Storage stability}

Hot storage stability test is applied to estimate high temperature stability of the modified bitumen under storage conditions. Tube test (PN-EN 13399) specification was followed; aluminum foil tube was filled up with melted modified binder and stored vertically inside the oven for 72 hours at a temperature of $163^{\circ} \mathrm{C}$. After the samples reach the predefined time, they are moved out and cooled at a 
temperature of $-20 \quad{ }^{\circ} \mathrm{C}$ for 4 hours using a refrigerator. The samples were then cut into three equal sections. The samples stability under high temperature storage conditions was considered by evaluation of the difference in softening point temperature between the bottom and top section. For stable samples, the difference in softening point falls below $4{ }^{\circ} \mathrm{C}$ (Yusoff et al., 2014).

\subsection{Temperature susceptibility}

Resistance to temperature for the modified binders was evaluated in terms of penetration index (PI). Temperature susceptibility of bitumen is described to be the change in its rheological parameters as a function of temperature. Results from softening point temperature and penetration are used to obtain PI. The estimation of penetration index is obtained from Shell Bitumen Hand book (Read and Whiteoak, 2003) using Eq. 1.

$P I_{T R \& B}=\frac{1952-500 \log P_{25}-20 T_{R \& B}}{500 \log P_{25}-T_{R \& B}-120}$

where $P I_{T R \& B}$ is the penetration index, $P_{25}$ is the binder penetration tested at $25{ }^{\circ} \mathrm{C}$, and $T_{R \& B}$ refers to samples softening point temperature.

\subsection{Scanning electron microscope (SEM)}

The modified binders SEM images were taken using adequately high resolution, field emission scanning electron microscope (FE-SEM) equipped with a cryogenic stage for minimizing the binders structural changes during scanning due to heating by electron beams. Flash frozen were applied to the binder samples before placing in the SEM chamber using a liquid nitrogen, the samples were scan at a pressure of $30 \mathrm{~Pa}$ and temperature of $-26^{\circ} \mathrm{C}$.

\subsection{Fourier transform infrared spectroscopy (FT-IR)}

The Fourier Transform Infrared Spectroscopy (FT-IR) of composite nanosilica/polyethylene modified bitumens was conducted using NEXUS670 FT-IR spectrometer. FT-IR spectra were conducted to evaluate interatomic chemical bonds changes through measurement of absorbed light at each wavelength. FT-IR spectroscopy was conducted in the wavenumber range of 4000 to $400 \mathrm{~cm}^{-1}$ at a scanning rate of $64 / \mathrm{min}$ and resolution of $4 \mathrm{~cm}^{-1}$.

\subsection{Dynamic shear rheometer (DSR) test}

The most common technique applied in determining the fundamental rheological characteristics of modified binders is using DSR oscillatory dynamic mechanical analysis. DSR temperature sweep test was carried out in a controlled strain at constant frequency rate of 10 $\mathrm{rad} / \mathrm{s}$. To ensure the test conducted is within linear viscoelastic range (LVE), the applied strain force was kept at minimum $0.2 \%$ within the LVE response. Temperature range for the test is between $20^{\circ} \mathrm{C}$ to $60{ }^{\circ} \mathrm{C}$ with temperature rise rate of $2{ }^{\circ} \mathrm{C} / \mathrm{min}$.

\subsection{Aging method}

RTFOT aging was conducted in accordance to ASTM D2872 standard specification to simulate the short term aging occurrence caused by oxidation which usually happens during mixing of binders. Binder samples of 35 grams weight were poured into RTFOT glass containers. The containers with binder samples were then placed in the RTFOT carriage with the top opening of the containers directly facing a jet of air inside and then closed. Aging process continues for 85 minutes with the carriage rotating at speed of $15 \mathrm{rpm}$ at an uninterrupted temperature of $163^{\circ} \mathrm{C}$.

\section{Result and discussion}

\subsection{Scanning electron microscope}

The SEM images of control and nanosilica modified binders are all shown in Fig. 1. For the control polymer modified binder (Fig. 1a), it can be observed that the surface is rough, as a result of continuous polymer phase that absorbs the maltenes fraction thereby inducing a difference on the surface of the bitumen. Fig. $1 \mathrm{~b}$ to $1 \mathrm{~g}$ shows a significant change in microstructure within the nanosilica modified binders by observing well dispersed images of nanosilica in the asphalt matrix compared to the control LLDPE polymer modified bitumen. This indicates that nanosilica particle has an extreme tendency to reacts with the bitumen binder, and form a new structure. The well dispersed structure observed in nanosilica modified binders can attributed to the high surface area and energy of nanosilica group which reacts and glued uniformly with the polyethylene and bitumen binder there by inhibiting aggregation of polyethylene particles and strengthening the binding capacity of polyethylene and bitumen.

\subsection{Fourier transforms infrared spectroscopy}

FT-IR spectroscopy is employed to check if there is changes chemical bonding between control and nanosilica modified binder. Fig. 2 presents the FT-IR spectra for the control and composite nanosilica modified binders. As depicted in Fig. 2a, it is evident that FT-IR spectra of all composite nanosilica modified binders differ from control between 400 $\mathrm{cm}-1$ to $500 \mathrm{~cm}^{-1}$ and $900 \mathrm{~cm}^{-1}$ to $1200 \mathrm{~cm}^{-1}$ respectively, the strong stretching peaks at 2918.29 $\mathrm{cm}-1$ and $2849.52 \mathrm{~cm}^{-1}$ are attributed due to $\mathrm{C}-\mathrm{H}$ stretching in aliphatic chains. Broad peaks observed at $1375.39 \mathrm{~cm}^{-1}$ are resulted due to bending vibration of branched aliphatic band $\mathrm{C}-\mathrm{H}$ of - (CH2) $\mathrm{n}$ - and $1456.39 \mathrm{~cm}-1$ are resulted due to asymmetrical bending vibration of aliphatic index C- 
$\mathrm{H}$ of $\mathrm{CH}_{3}$. The peaks absorbed at $1098.09 \mathrm{~cm}^{-1}$, $807.20 \mathrm{~cm}^{-1}$ and $462.05 \mathrm{~cm}^{-1}$ in the spectra of composite modified binders were due to stretching,

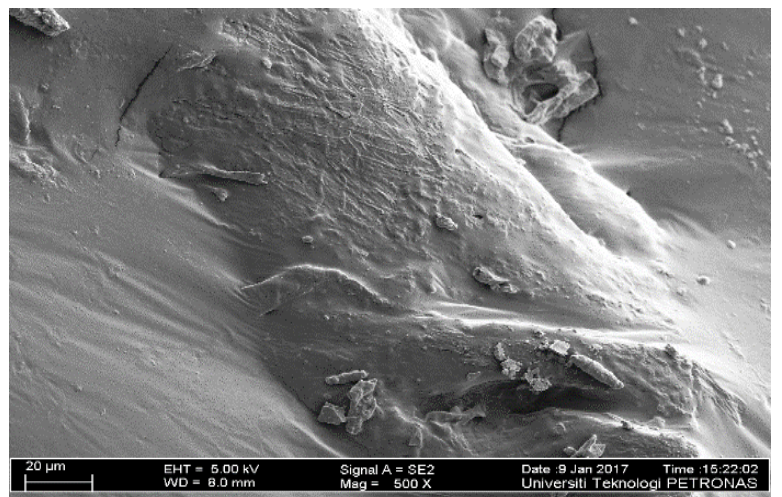

(a)

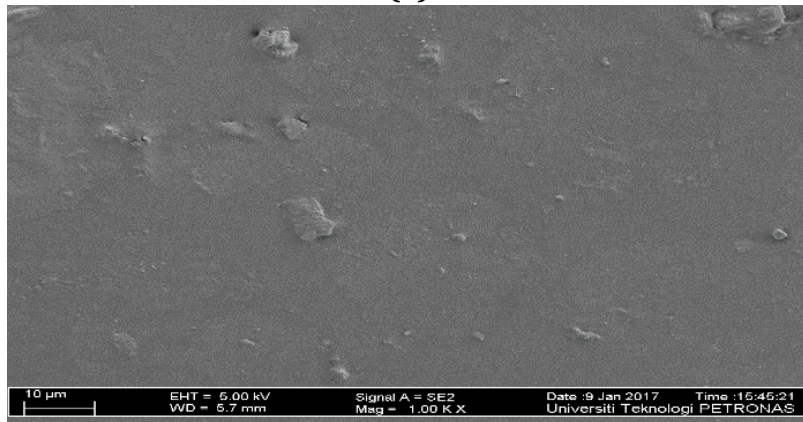

(c)

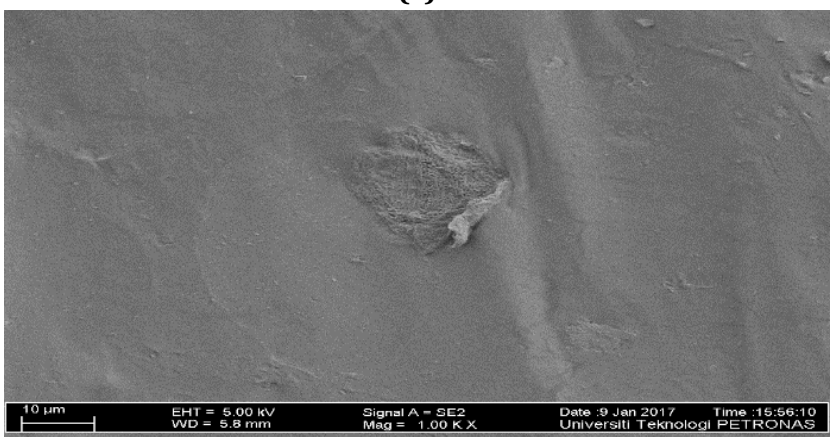

(e)

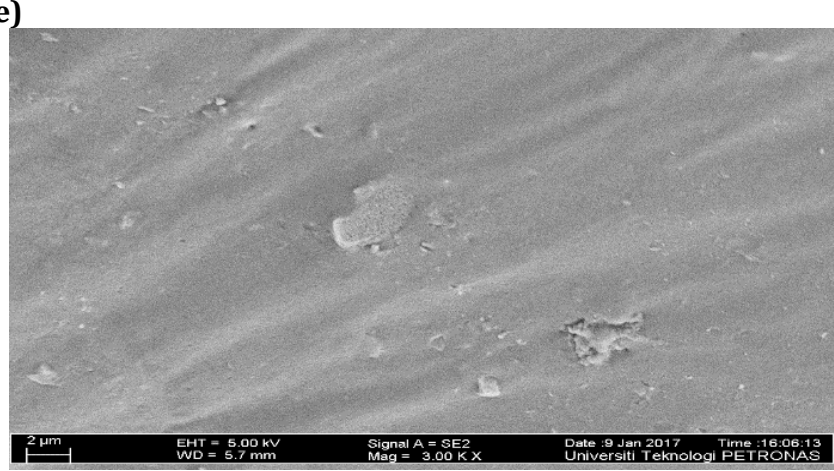

(g)

Fig. 1: FE-SEM microstructure images of control and nanosilica modified binders (a) PE control binder (b) PE+1\% nanosilica modified binder (c) PE+2\% nanosilica (d) PE+3\% nanosilica (d) PE+4\% nanosilica (e) PE+5\% nanosilica (f) PE+6\% nanosilica

To evaluate the aging behavior of nanosilica modified binders, FT-IR spectral bands signal centered around $1600 \mathrm{~cm}^{-1}$ to $1700 \mathrm{~cm}^{-1}$ that show carbonyl functional groups $\mathrm{C}=\mathrm{O}$ formation as a result of binders exposure to oxygen under high temperatures are used (Feng et al., 2013; Mouillet et al., 2008). From Fig. $2 \mathrm{a}$ to $2 \mathrm{f}$, it is evident that the $\mathrm{C}=\mathrm{O}$ peak intensity found to be the lowest for bending and rocking vibration of Si-O-Si. This was further confirmed by findings by Moore et al. (2003) and Zhang and Zhang (2015).

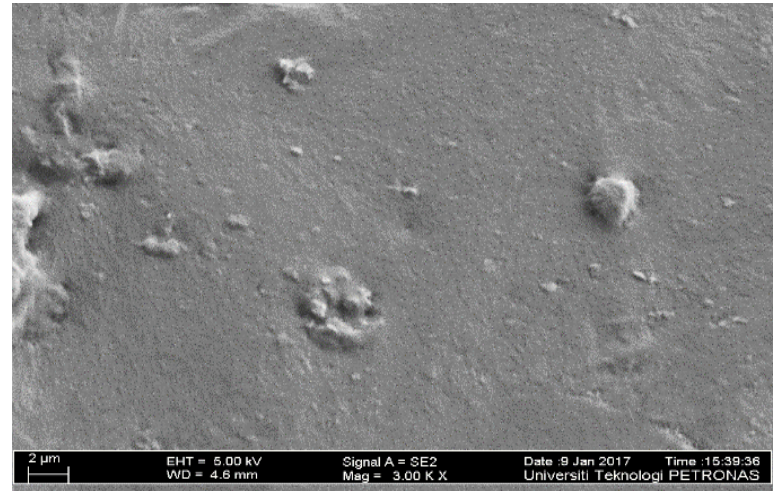

(b)

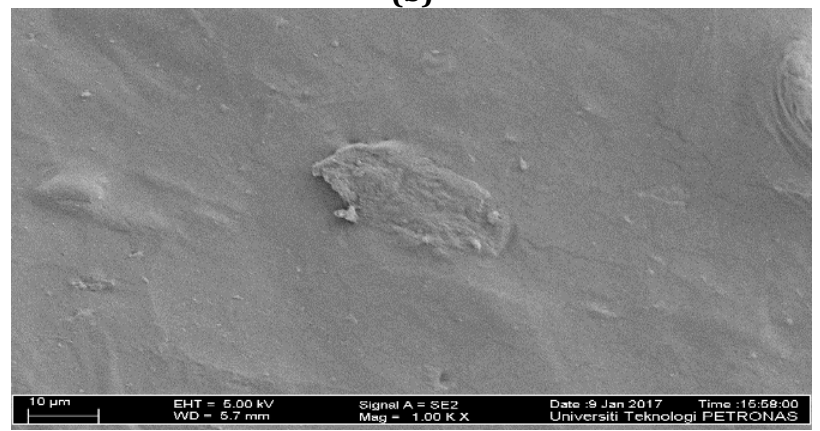

(d)

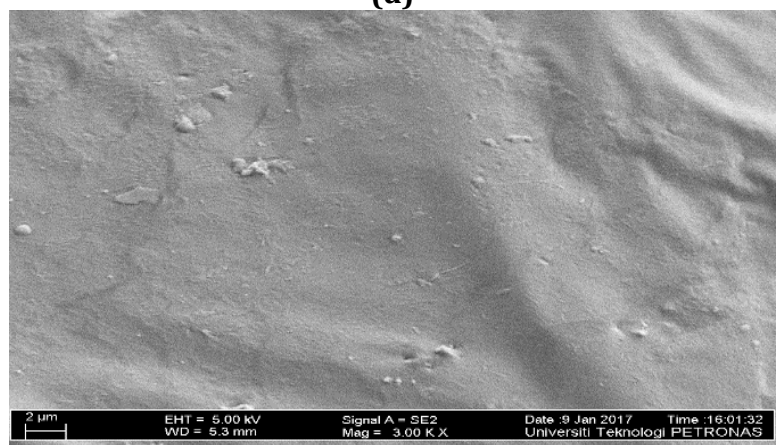

(f) 


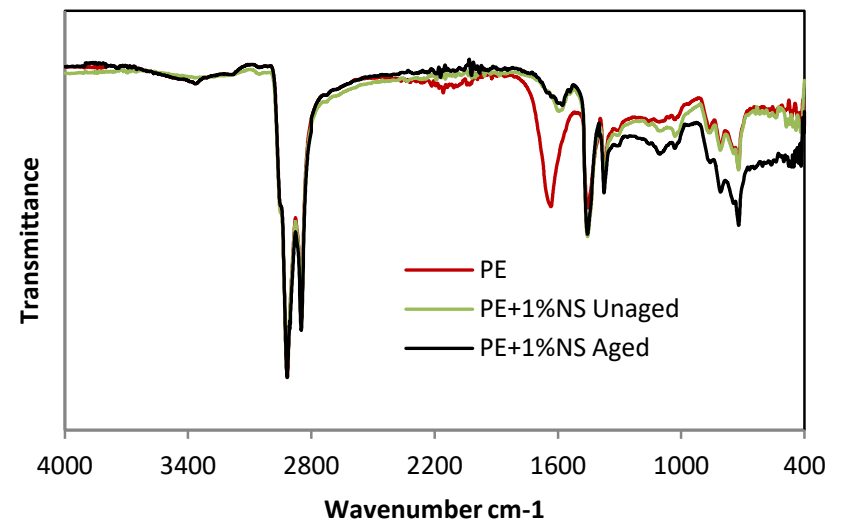

(a)

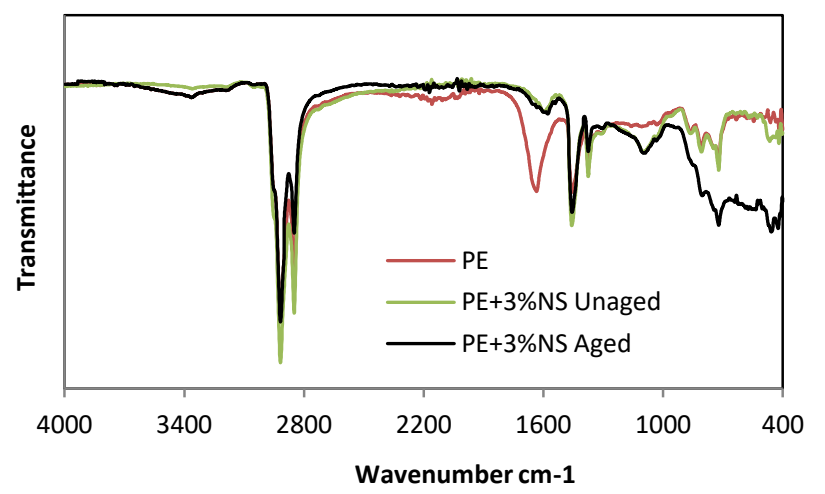

(c)

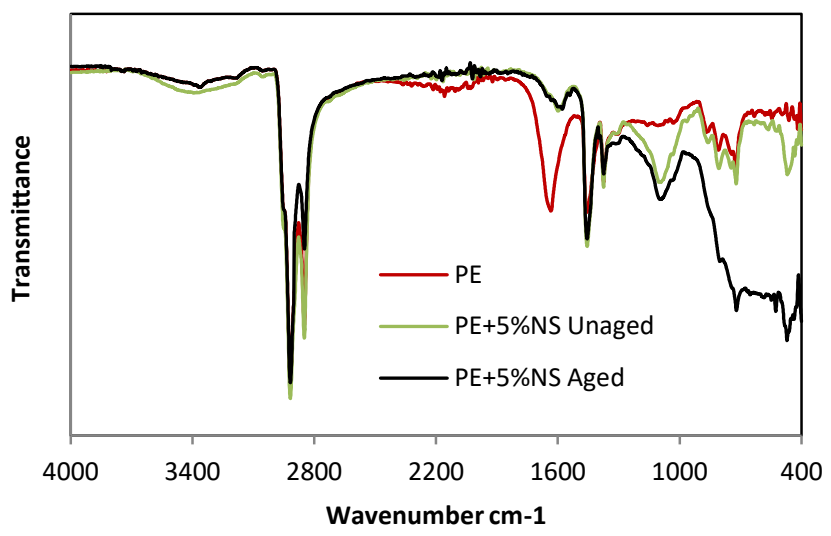

(e)

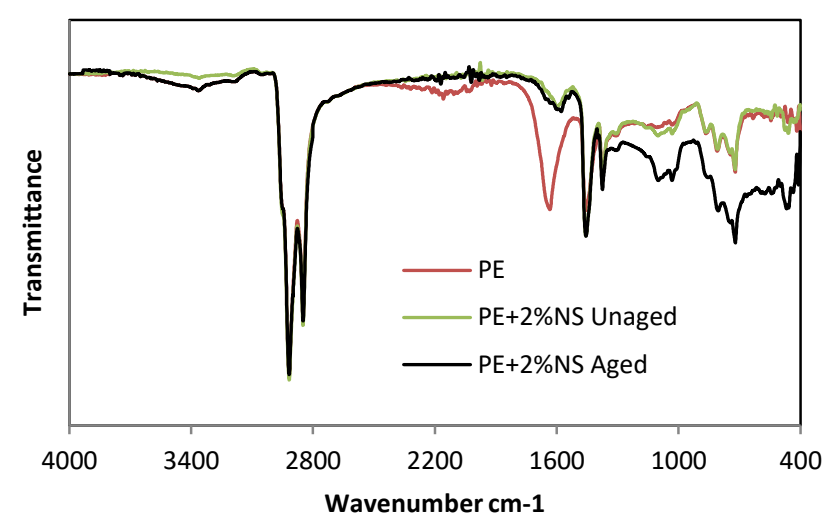

(b)

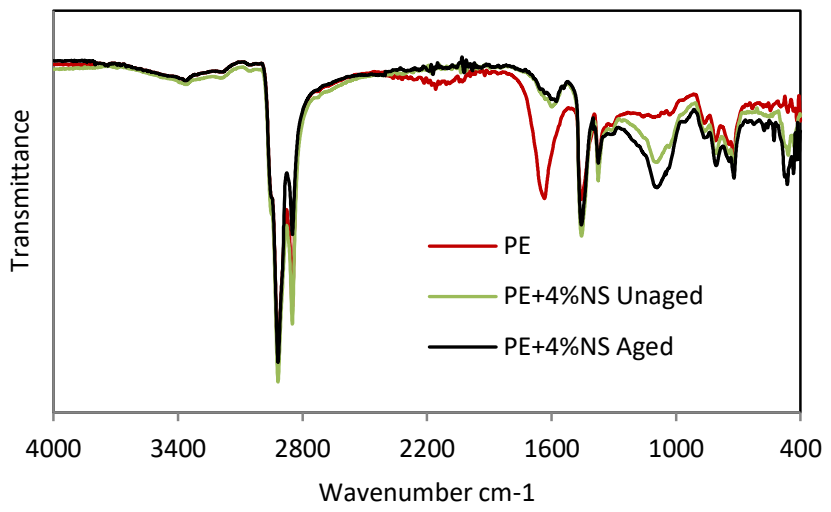

(d)

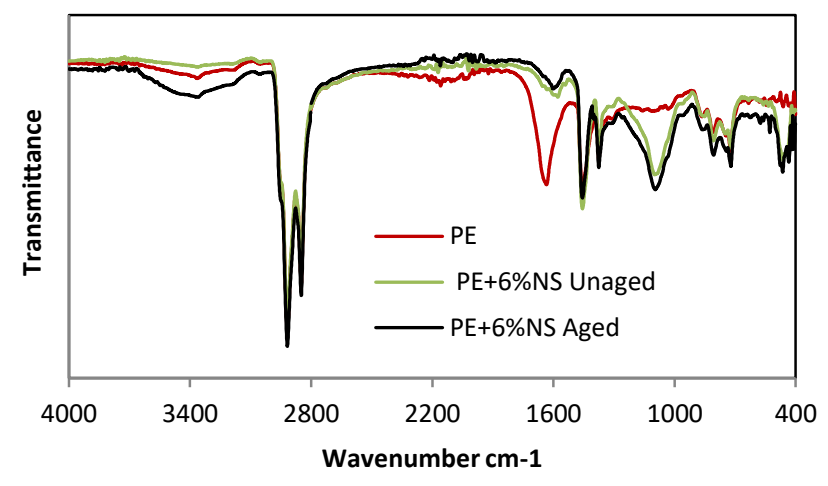

(f)

Fig. 2: FTIR spectroscopy analysis of control, unaged and aged nanosilica modified binders (a) $1 \%$ nanosilica (b) $2 \%$ nanosilica (c) $3 \%$ nanosilica (d) $4 \%$ nanosilica (e) $5 \%$ nanosilica (f) $6 \%$ nanosilica

This consequently delay oxidative aging in the modified binder, the reduction in aging can be attributed to the large pore size, the huge surface area of interaction of nanosilica particles and hydroxyl groups presence on the surface of nanosilica, because the oxygen atom presence in the hydroxyl groups on the surface of nanosilica has higher electronegativity than the hydrogen atoms. This makes it more easily to form hydrogen bonds with aromatic sheets in polar aromatics and asphaltene molecules in the bitumen and that type of interactions decreases the proneness to oxidation of polar aromatics and asphaltene molecules, which have both shown to be quite prone to oxidation, a similar phenomenon was also observed by Fini et al. (2015).

\subsection{Storage stability}

Storage stability was evaluated to confirm that, the effectiveness of additives used was not changed through modification processes. Softening point temperatures for the top, as well as bottom sections of nanosilica composite modified binder samples and their differences, are presented in Table 3. It can be observed that all nanosilica modified binders have top and bottom sections difference of less than $4^{\circ} \mathrm{C}$, this indicates that at all nanosilica concentrations the composite modified binder samples will be stable under high temperature storage. However, the control LLDPE polymer modified binder shows the highest temperature difference of $7^{\circ} \mathrm{C}$, which is above the minimum $4^{\circ} \mathrm{C}$ required, this indicates that 
LLDPE modified binder will exhibit phase during storage especially at high temperatures.

\subsection{Temperature susceptibility}

The susceptibility to temperature effects is the change in rheological properties of binders with a change in temperature. The PI value generally ranges from -3 (highly temperature susceptibility bitumen) to +7 (highly blown low temperature susceptibility) (Read and Whiteoak, 2003; Samsudin et al., 2016). Fig. 3 shows the penetration index of control LLDPE and composite nanosilica modified binders, it can be observed that the composite nanosilica modified binders have higher PI values compared to control LLDPE polymer modified binder, this indicates that composite nanosilica modified binders are less susceptible to temperature compared to control. An increase in PI values up to $4 \%$ nanosilica content was observed after aging this shows that oxidative aging will not have an influence on nanosilica modified binders. This result confirms that nanosilica has a positive effect on enhancing temperature susceptibility of polymer modified binders.

\subsection{Isochronal plots}

The temperature dependencies of complex modulus, viscosity as well as phase angle for both control LLDPE and composite nanosilica modified binders before and after RTFOT aging are presented in Fig. 4 through 6, respectively.

It is observed from Figs. 4 and 5 that complex modulus and viscosity for composites increases with the addition of nanosilica in the binders, while in Fig. 8 , phase angle values reduce with an increase in nanosilica content.

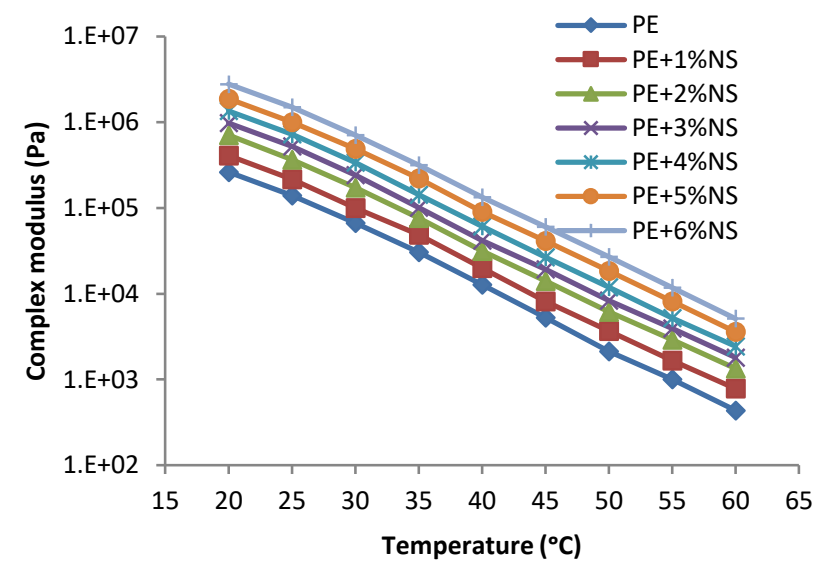

(a)

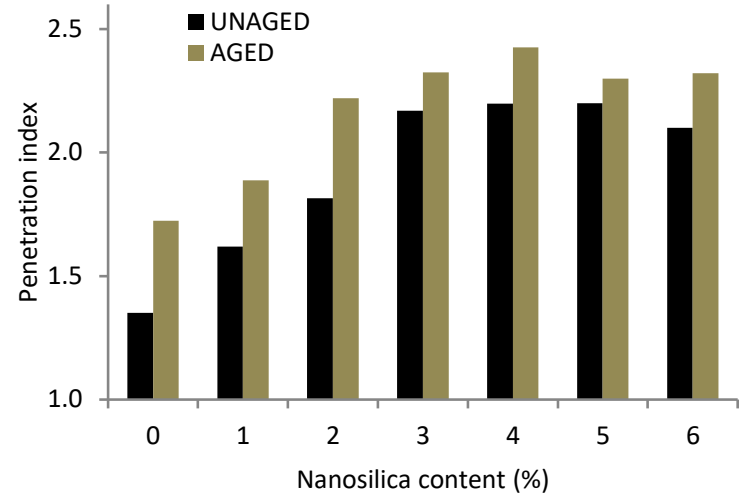

Fig. 3: Penetration index for modified binders before and after aging

Comparing nanosilica modified binders with the control, it is apparent that an increase in values was observed with nanosilica modified binders, this indicates that nanosilica modified binders are more elastic in their behaviors compared to control LLDPE polymer modified binders; this property will make them more resistant to permanent deformations.

However comparing unaged and RTFOT aged samples Figs. $4 \mathrm{a}$ and $4 \mathrm{~b}$ and Figs. $5 \mathrm{a}$ and $5 \mathrm{~b}$ respectively, it can be seen that the complex modulus and viscosities for aged samples are higher than that of the unaged binders. It can also be observed that the complex modulus decreases almost with increase in nanosilica content especially at high temperatures; this indicates high resistance of the binders to age-hardening.

However, for phase angle plot in Figs. 6a and 6b, it shows an opposite phenomenon, that is, aged binder samples are lower than unaged binder samples, and this implies that RTFOT aging improves the viscoelastic properties of composite nanosilica modified binders.

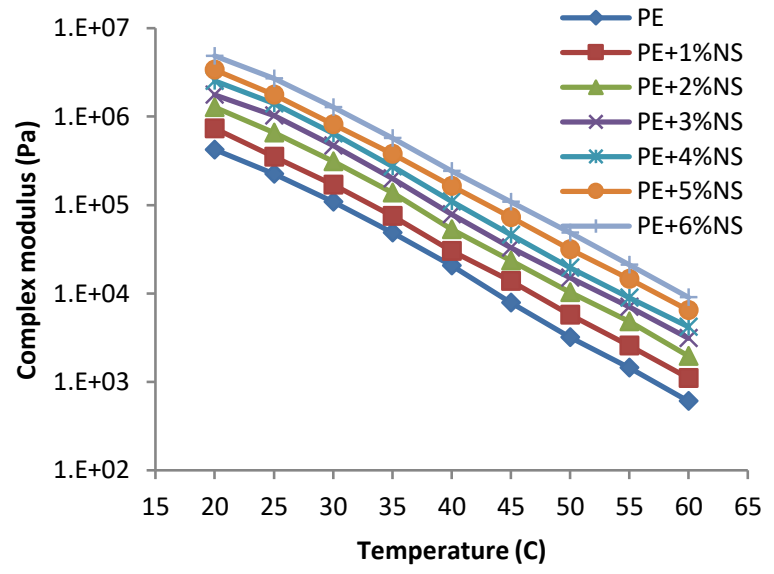

(b)

Fig. 4: Isochronal plots of temperature and complex modulus: (a) Unaged LLDPE and nanosilica modified binders; (b) RTFOT aged LLDPE and nanosilica modified binders

Also the increase in viscosity observed will results in formation of strong film of binder around the aggregates which will improve the cohesive bond between binder and aggregates. The increase in complex modulus and decrease in phase angle observed in the composite nanosilica modified binders after RTFOT aging indicates an increase in elastic behavior of the binders. 


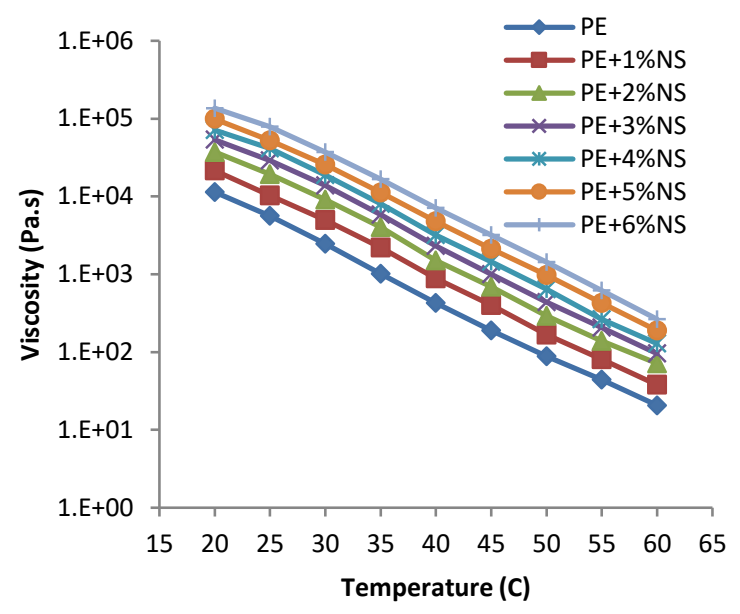

(a)

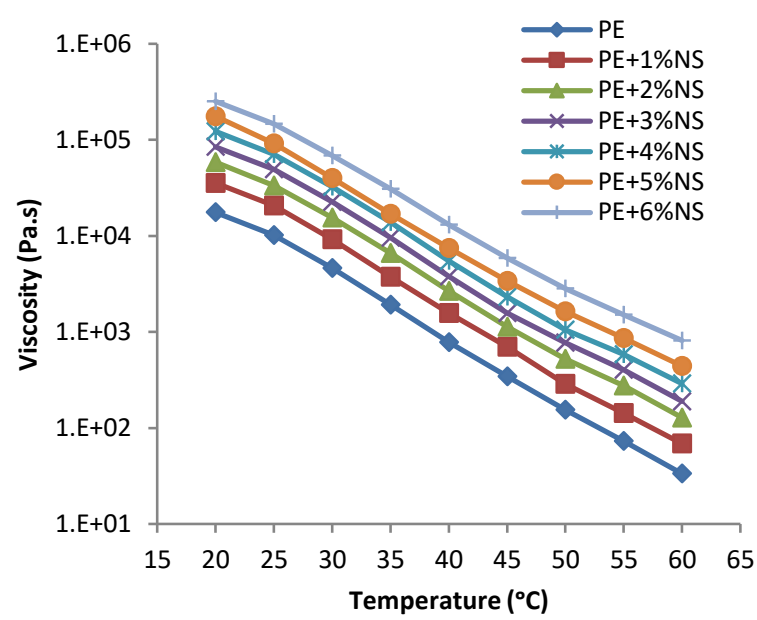

(b)

Fig. 5: Isochronal plots of temperature and viscosity: (a) Unaged LLDPE and nanosilica modified binders; (b) RTFOT aged LLDPE and nanosilica modified binders

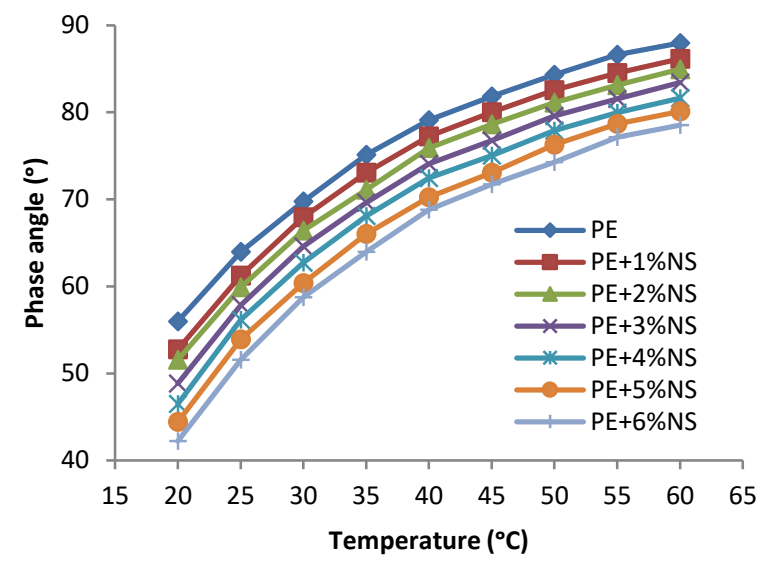

(a)

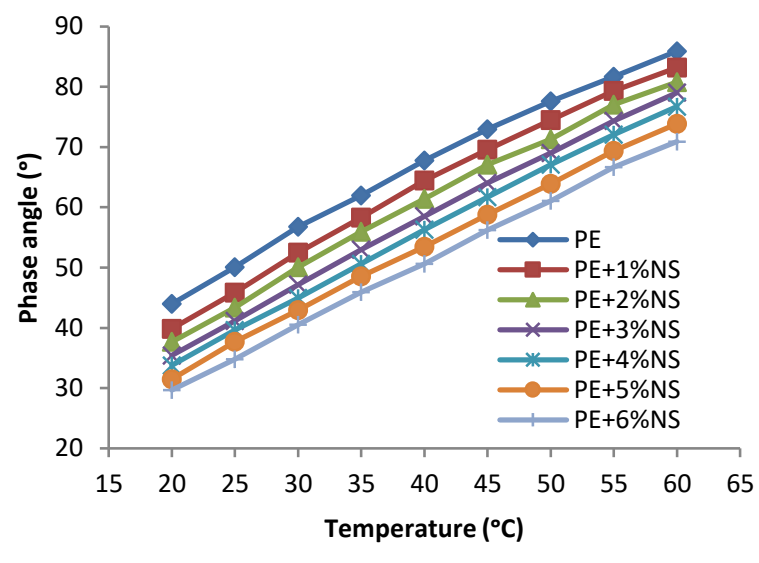

(b)

Fig. 6: Isochronal plots of phase angle: (a) Unaged control and nanosilica modified binders; (b) RTFOT aged control and nanosilica modified binders

\subsection{Superpave rutting parameter}

For further investigation of modified binders, resistance to deformation, a Superpave rutting parameter $\mathrm{G}^{*} / \sin \delta$ ratio was evaluated before and after binders aging. $\mathrm{G}^{*} / \sin \delta$ ratio describes resistance of bituminous binders against rutting defects under high temperature conditions. Superpave rutting criteria require $\mathrm{G}^{*} / \sin \delta \geq 1 \mathrm{kPa}$ and $\mathrm{G}^{*} / \sin \delta \geq 2.2 \mathrm{kPa}$ respectively (Kennedy et al., 1994 ) to be the minimum required values of rutting parameter for an unaged and aged binders.

Fig. 7 shows the effects of temperature on the rutting resistance of the modified binders. It can be observed that, both before and after binders RTFOT aging, the control modified binder shows the least value for $\mathrm{G}^{*} / \sin \delta$ ratio. From both unaged binders (Fig. 9a) and RTFOT aged binders (Fig. 9b), it can be seen that, at the highest test temperature of $60{ }^{\circ} \mathrm{C}$, all nanocomposite modified binders with exception of $1 \%$ nanosilica have $\mathrm{G}^{*} / \sin \delta$ ratio values greater than the minimum required value specified by the Superpave. The lower value of $\mathrm{G}^{*} / \sin \delta$ ratio observed in $1 \%$ nanosilica may be attributed to the insufficient amount of nanosilica which makes it behave as control binder. This indicates that addition of nanosilica into LLDPE polymer modified binder decreases the rate of oxidation in the binders; this reduces hardening of the binder during aging process which leads to an improvement in the binders resistance against permanent deformation.

Table 3: Hot storage temperature stability

\begin{tabular}{cccc}
\hline \multirow{2}{*}{ Binder } & \multicolumn{3}{c}{ Softening point temperature $\left({ }^{\circ} \mathrm{C}\right)$} \\
\cline { 2 - 4 } & Top & Bottom & Difference $_{(\text {Top-Bottom })}$ \\
\hline PE & 69.3 & 62.5 & 6.8 \\
PE + 1\% NS & 53.9 & 51.6 & 2.3 \\
PE + 2\% NS & 56.6 & 54.5 & 2.1 \\
PE + 3\% NS & 59.9 & 57.9 & 2.0 \\
PE + 4\% NS & 61.3 & 59.4 & 1.9 \\
PE + 5\% NS & 65.9 & 64.1 & 1.8 \\
PE + 6\% NS & 63.4 & 61.3 & 2.1 \\
\hline
\end{tabular}

\subsection{Fail temperature}

Superpave failure temperature is a critical temperature for bituminous binder sample under which the time temperature equivalence principle is no longer applicable (Chen et al., 2014). Superpave standard specification describes failure temperature for bituminous binders, to be the temperature under which of the ratio of $\mathrm{G}^{*} / \sin \delta$ falls below a value of $1.0 \mathrm{kPa}$ (Kennedy et al., 1994). A high failure 
temperature indicates high resistance to deformation.

Fig. 8 presents the influence of nanosilica content on the failure temperature of modified binder samples. It can be observed that nanosilica modified binders show higher fail temperatures; this result will make them more difficult to yield a permanent

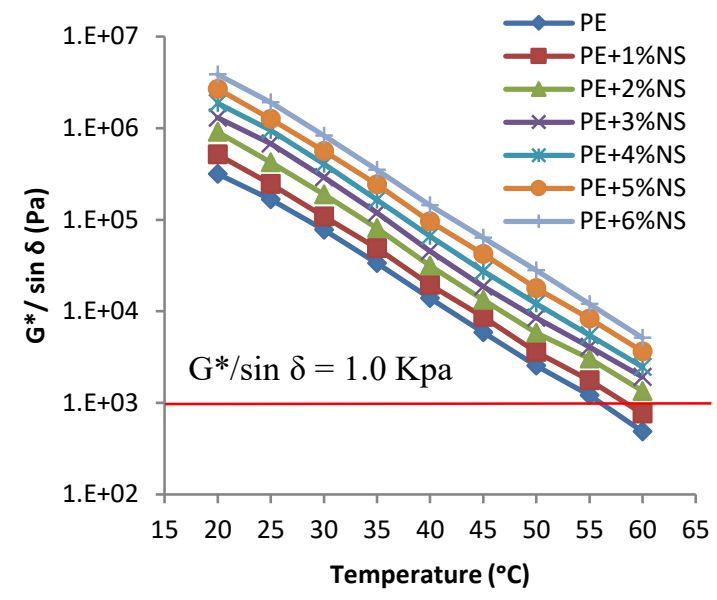

(a) deformation at higher pavement service temperatures (Lee et al., 2009). Higher fail temperatures observed can be attributed due to sufficient surface area of interaction for nanosilica which makes LLDPE and bitumen to be more compatible and highly stable.

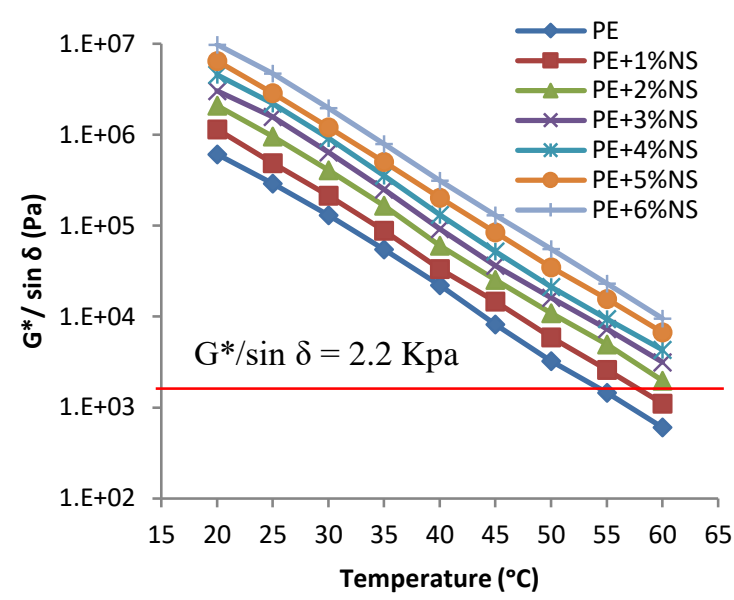

(b)

Fig. 7: Temperature effects on the rutting resistance of (a) LLDPE and nanosilica modified binder before aging. (b) LLDPE and nanosilica modified binder after aging

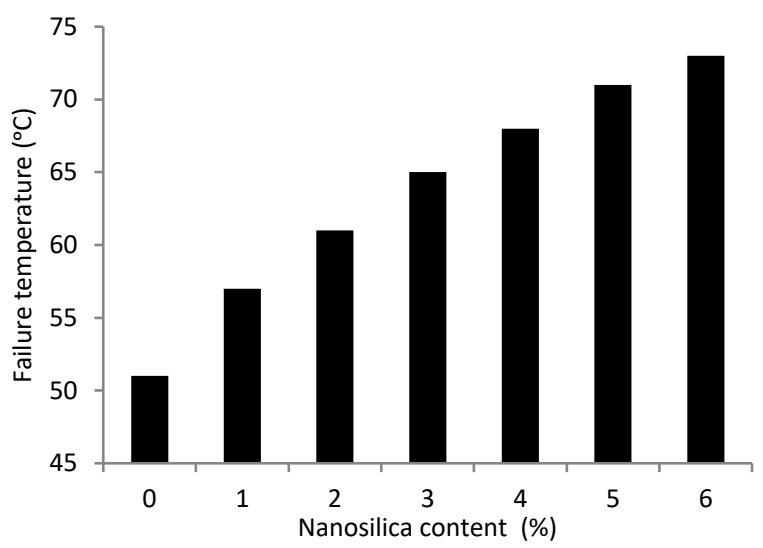

Fig. 8: Superpave failed temperature for modified binders

\subsection{Viscosity aging index}

Viscosity aging index (VAI) is a parameter calculated for estimating the degree of aging resistance of bitumen binder. Lower values of VAI generally describe binders higher resistance to oxidative aging. VAI is computed as in Eq. 2.

$V A I=\left(\frac{\text { Aged }_{\text {viscosity }}-\text { Unaged }_{\text {viscosity }}}{\text { Unaged }_{\text {viscosity }}}\right) \times 100$

where VAI stands for viscosity aging index, Aged $_{\text {viscosity }}$ and Unaged $_{\text {viscosity }}$ are aged as well as unaged viscosity. Fig. 9 presents the viscosity aging index of the modified binder, it can be noted that, composite nanosilica modified binders significantly have less VAI compared to control LLDPE polymer modified binder and the VAI for composites nanosilica modified binders continuously decreases with increase in nanosilica contents, with 5\% nanosilica content showing the least VAI value of $67 \%$ among, this shows that nanosilica can protect the modified binder against oxidative aging effects. The enhancement observed in oxidative aging within nanosilica modified binder samples can also be attributed due to high surface area ratio of dispersed nano silicate layers in the binder that efficiently protects oxygen penetration and loss of volatile components during the aging process of the modified binders, which eventually promotes binders resistance to oxidative aging.

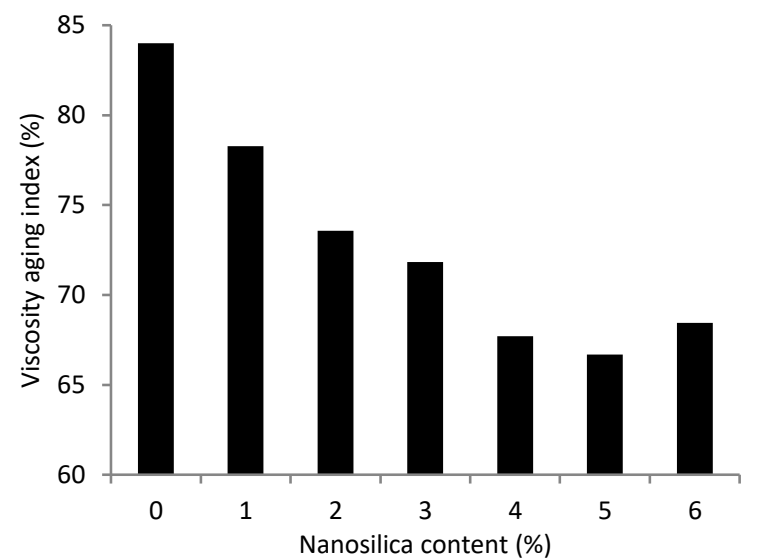

Fig. 9: Effect of aging on complex viscosity of modified binders

\subsection{High temperature aging Index}

A high temperature aging indices (HTAI) is used to estimate changes in binder oxidation levels under high in-service temperature conditions. Generally, a greater value of HTAI shows binders poor resistance 
to aging. HTAI is computed as Eq. 3 (Dessouky et al., 2011):

$$
H T A I=\frac{G^{*} / \sin \delta_{R T F O T a g e d}}{G^{*} / \sin \delta_{(\text {unaged })}}
$$

where HTAI is the high temperature aging index, $\mathrm{G}^{*} /$ $\sin \delta$ (RTFOT aged) and $\mathrm{G}^{*} / \sin \delta$ (Unaged) are $\mathrm{G}^{*} / \sin \delta$ ratios of RTFOT aged and unaged binders. Fig. 10 presents high temperature aging index values for control and nanosilica modified binders. It is observed that nanosilica modified binders exhibit the least values of HTAI compared to control binder. This enhancement in HTAI can be attributed to the decrease in binder oxidation level during aging process which minimizes binder stiffness increment.

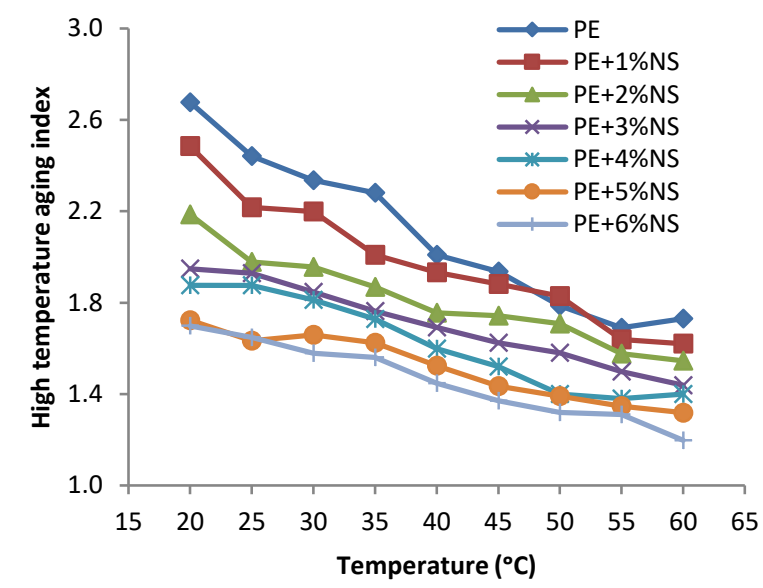

Fig. 10: Effect of high temperature aging on LLDPE and nanosilica modified binders

$\mathrm{G}^{*} / \sin \delta$ ratio increment is another useful parameter that describes the degree of aging in bitumen binder. $\mathrm{G}^{*} / \sin \delta$ increment is denoted as $\Delta \mathrm{G}^{*} / \sin \delta$ and is computed as Eq. 4 .

$\Delta G^{*} / \sin \delta=G^{*} / \sin \delta_{\text {Aged }}-G^{*} / \sin \delta_{(\text {unaged })}$

where $\Delta \mathrm{G}^{*} / \sin \delta$ refers to increment in $\mathrm{G}^{*} / \sin \delta$ ratio, $\mathrm{G}^{*} / \sin \delta$ (Aged) and $\mathrm{G}^{*} / \sin \delta$ (Unaged) are $\mathrm{G}^{*} / \sin \delta$ ratios of binders both before and after aging respectively. Fig. 11 presents the increment in $\mathrm{G}^{*} / \mathrm{sin}$ $\delta$ ratios after binders RTFOT aging. As seen, nanosilica modified binders shows a remarkable reduction in $\Delta \mathrm{G}^{*} / \sin \delta$ compared to LLDPE polymer modified binder. Also, it is evident from the results that, 5 and $6 \%$ nanosilica modified binders have the lowest $\Delta \mathrm{G}^{*} / \sin \delta$ ratio increment, this indicates that they will be more resistance to thermo oxidative aging.

\subsection{Softening point increment}

Softening point increment (SPI) is used to indicate a susceptive degree of aging in bituminous binders. SPI present changes in softening point values before and after RTFOT aging which reflects aging susceptibility of the binder. SPI is denoted as $\Delta S$ and is computed as in Eq. 5.

$\Delta S=S P_{(\text {Aged })}-S P_{(\text {Unaged })}$ where $\Delta S$ refers to increment in softening point, $\mathrm{SP}_{\text {(aged) }}$ is aged softening point and $\mathrm{SP}_{\text {(unaged) is the }}$ unaged softening point. Fig. 12 presents the softening point increment changes of composite nanosilica and control LLDPE modified bitumen after RTFOT aging. It can be observed that, composite nanosilica modified binders exhibits the least softening point increment values. This shows that addition of nanosilica in to LLDPE polymer modified binder have an important effect on enhancing aging resistance of the modified binders due to lower hardening aging observed in the binders.

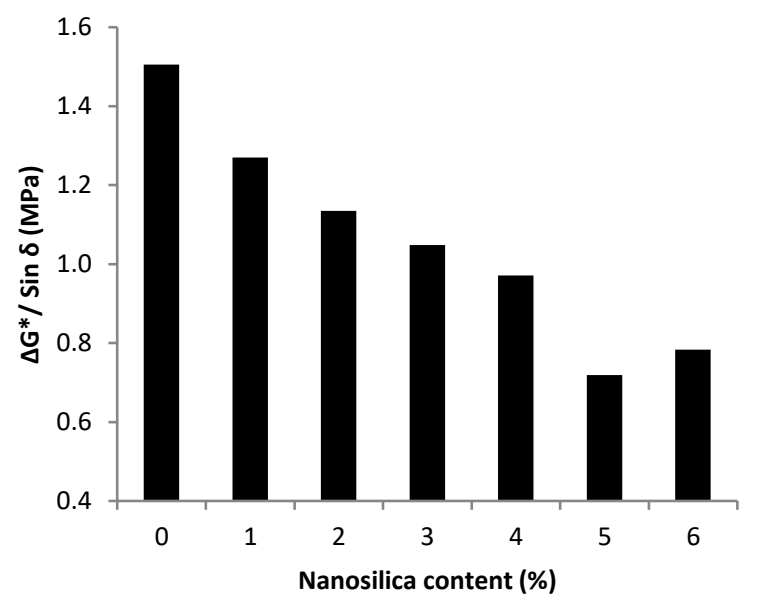

Fig. 11: Effect of aging on $\mathrm{G}^{*} / \sin \delta$ on LLDPE and nanosilica modified binders

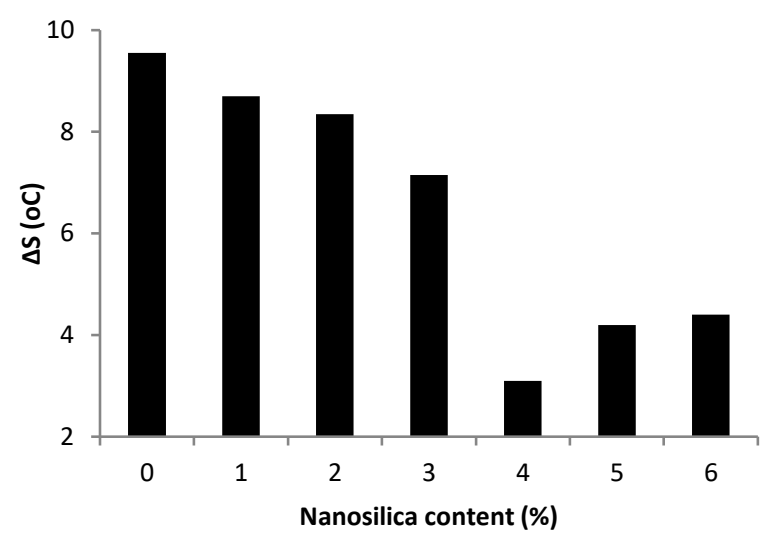

Fig. 12: Softening point increment of LLDPE and nanosilica modified binders

\section{Conclusion}

In this investigation, the properties of composite nanosilica modified binders in comparison with LLDPE polymer modified bitumen were investigated. SEM analysis shows an excellent dispersion of nanosilica and polyethylene within the modified binders, which indicates that nanosilica, can significantly improve the compatibility between bitumen and polyethylene. Storage stability test for nanocomposite modified binders indicates that all nanosilica modified binder will be stable under high temperature storage conditions due to the ability of nanosilica to form a strong bond between LLDPE and bitumen. Furthermore, the Superpave viscosity aging index showed that nanosilica can reduce aging due 
to reduction of VAI in the nanosilica modified binders, the FT-IR spectrums results showed that nanosilica can delay the process of oxidative aging in the modified binders, this was confirmed by reduction in the carbonyl group formation which is attributed to the nanosilica huge surface area as well as hydroxyl groups presence.

\section{Acknowledgement}

The authors wish to express their gratitude to Universiti Teknologi PETRONAS (UTP) for providing all necessary facilities, for conducting the experiments and also to all technologist in Highway laboratory of Civil Engineering Department.

\section{References}

Airey GD (2003). Rheological properties of styrene butadiene styrene polymer modified road bitumens. Fuel, 82(14): 1709 1719.

Bala N and Kamaruddin I (2016). Physical and storage stability properties of linear low density polyethylene at optimum content. In the Engineering Challenges for Sustainable Future: $3^{\text {rd }}$ International Conference on Civil, Offshore and Environmental Engineering, CRC Press, Malaysia.

Bala N, Kamaruddin I, Napiah M, and Danlami N (2017). Rheological and rutting evaluation of composite nanosilica/polyethylene modified bitumen. In the $7^{\text {th }}$ International Conference on Key Engineering Materials, IOP Conference Series: Materials Science and Engineering, IOP Publishing, Penang, Malaysia: 1-6. https://doi.org/10.1088/ 1757-899X/201/1/012012

Chen M, Xiao F, Putman B, Leng B, and Wu S (2014). High temperature properties of rejuvenating recovered binder with rejuvenator, waste cooking and cotton seed oils. Construction and Building Materials, 59: 10-16.

Dessouky S, Reyes C, Ilias M, Contreras D, and Papagiannakis A (2011). Effect of pre-heating duration and temperature conditioning on the rheological properties of bitumen. Construction and Building Materials, 25(6): 2785-2792.

Fang C, Li T, Zhang Z, and Wang X (2008). Combined modification of asphalt by waste PE and rubber. Polymer Composites, 29(10): 1183-1187.

Fang C, Yu R, Liu S, and Li Y (2013). Nanomaterials applied in asphalt modification: A review. Journal of Materials Science and Technology, 29(7): 589-594.

Fawcett A, McNally T, McNally G, Andrews F, and Clarke J (1999). Blends of bitumen with polyethylenes. Polymer, 40(23): 6337 6349.

Feng ZG, Yu JY, Zhang HL, Kuang DL, and Xue LH (2013). Effect of ultraviolet aging on rheology, chemistry and morphology of ultraviolet absorber modified bitumen. Materials and Structures, 46(7): 1123-1132.

Fini EH, Hajikarimi P, Rahi M, and Moghadas Nejad F (2015). Physiochemical, rheological, and oxidative aging characteristics of asphalt binder in the presence of mesoporous silica nanoparticles. Journal of Materials in Civil Engineering, 28(2): 04015133. https://doi.org/10.1061/ (ASCE)MT.1943-5533.0001423

Kennedy TW, Huber GA, Harrigan ET, Cominsky RJ, Hughes CS, Von Quintus H, and Moulthrop JS (1994). Superior performing asphalt pavements (Superpave): The product of the SHRP asphalt research program (No. SHRP-A-410). Strategic Highway Research Program, National Research Council, Washington, D.C., USA.
Lee SJ, Amirkhanian SN, Park NW, and Kim KW (2009). Characterization of warm mix asphalt binders containing artificially long-term aged binders. Construction and Building Materials, 23(6): 2371-2379.

Mahdi LM, Muniandy R, Yunus RB, Hasham S, and Aburkaba E (2013). Effect of short term aging on organic montmorillonite nanoclay modified asphalt. Indian Journal of Science and Technology, 6(10): 5434-5442.

Moore C, Perova TS, Kennedy B, Berwick K, Shaganov II, and Moore RA (2003). Study of structure and quality of different silicon oxides using FTIR and Raman microscopy. In the Conference of SPIE, Opto-Ireland 2002: Optics and Photonics Technologies and Applications, Galway, Ireland, 4876: 1247 1256. http:// doi.org/10.1117/12.464024

Mouillet V, Farcas F, and Besson S (2008). Ageing by UV radiation of an elastomer modified bitumen. Fuel, 87(12): 2408-2419.

Ouyang C, Wang S, Zhang Y, and Zhang Y (2006). Improving the aging resistance of styrene-butadiene-styrene tri-block copolymer modified asphalt by addition of antioxidants. Polymer Degradation and Stability, 91(4): 795-804.

Pérez-Lepe A, Martínez-Boza F, and Gallegos C (2005). Influence of polymer concentration on the microstructure and rheological properties of high-density polyethylene (HDPE)modified bitumen. Energy and Fuels, 19(3): 1148-1152.

Petersen JC (2000). Chemical composition of asphalt as related to asphalt durability. Developments in Petroleum Science, 40: 363-399.

Punith V and Veeraragavan A (2010). Behavior of reclaimed polyethylene modified asphalt cement for paving purposes. Journal of Materials in Civil Engineering, 23(6): 833-845.

Read J and Whiteoak D (2003). The shell bitumen handbook. Thomas Telford, London, UK.

Samsudin MS, Arshad AK, Ahmad J, and Masri KA (2016). Microstructure of nanosilica modified binder by atomic force microscopy. Jurnal Teknologi, 78(7-3): 33-44.

Santagata E, Baglieri O, Tsantilis L, and Dalmazzo D (2012). Rheological characterization of bituminous binders modified with carbon nanotubes. Procedia-Social and Behavioral Sciences, 53: 546-555.

Sengoz B and Isikyakar G (2008). Evaluation of the properties and microstructure of SBS and EVA polymer modified bitumen. Construction and Building Materials, 22(9): 1897-1905.

Yang J and Tighe S (2013). A review of advances of nanotechnology in asphalt mixtures. Procedia-Social and Behavioral Sciences, 96: 1269-1276.

Yao H, You Z, Li L, Lee CH, Wingard D, Yap YK, Goh SW (2012). Rheological properties and chemical bonding of asphalt modified with nanosilica. Journal of Materials in Civil Engineering, 25(11): 1619-1630.

Yu R, Fang C, Liu P, Liu X, and Li Y (2015). Storage stability and rheological properties of asphalt modified with waste packaging polyethylene and organic montmorillonite. Applied Clay Science, 104: 1-7.

Yusoff NIM, Breem AAS, Alattug HN, Hamim A, and Ahmad J (2014). The effects of moisture susceptibility and ageing conditions on nano-silica/polymer-modified asphalt mixtures. Construction and Building Materials, 72: 139-147.

Zhang $\mathrm{H}$ and Zhang D (2015). Effect of different inorganic nanoparticles on physical and ultraviolet aging properties of bitumen. Journal of Materials in Civil Engineering, 27(12): 04015049. https://doi.org/10.1061/(ASCE)MT.1943-5533. 0001321

Zhu J, Birgisson B, and Kringos N (2014). Polymer modification of bitumen: Advances and challenges. European Polymer Journal, 54: 18-38. 